\title{
Directional Control of the Structural Adsorption Properties of Clays by Magnetite Modification
}

\author{
Tetiana A. Dontsova $\left(\mathbb{D}^{1}{ }^{1}\right.$ Elena I. Yanushevskaya, ${ }^{1}$ Svitlana V. Nahirniak, ${ }^{1}$ \\ Oksana V. Makarchuk (D), ${ }^{1}$ Andrei I. Ivanets, ${ }^{1}$ Marina Yu Roshchina, \\ Anastasiya S. Kutuzova, ${ }^{1}$ and Leonid M. Kulikov ${ }^{2}$ \\ ${ }^{1}$ Department of Inorganic Substances, Water Purification and General Chemical Technology, National Technical University of \\ Ukraine "Igor Sikorsky Kyiv Polytechnic Institute", Kyiv 03056, Ukraine \\ ${ }^{2}$ Department of Fine Inorganic Synthesis, Thermodynamics and Kinetics of Heterophase Processes, Institute for Problems of \\ Materials Science, National Academy of Sciences of Ukraine, Kyiv 03142, Ukraine
}

Correspondence should be addressed to Tetiana A. Dontsova; dontsova@xtf.kpi.ua

Received 7 August 2018; Accepted 27 September 2018; Published 16 December 2018

Guest Editor: Vidyadhar Singh

Copyright (C) 2018 Tetiana A. Dontsova et al. This is an open access article distributed under the Creative Commons Attribution License, which permits unrestricted use, distribution, and reproduction in any medium, provided the original work is properly cited.

\begin{abstract}
This article presents the results of the study on the effect of nanomagnetite modification on textural characteristics of clay matrices, adsorption properties, and parameters of the spent sorbents separation. The nitrogen adsorption-desorption method has shown that the obtained magnetic nanocomposite sorbents have large specific surface areas (in 1.2-2 times more) than the initial clays due to the formation of the secondary porous structure on the surface and in macropores of clay matrices. The best adsorption properties with respect to dyes belong to magnetic sorbents with nanomagnetite content of $7 \mathrm{wt} . \%$. The additional modification of the third phase of graphene-like molybdenum disulphide into magnetic sorbents leads to the significant increase in the sorption capacity of both cationic (up to $1100 \mathrm{mg} / \mathrm{g}$ ) and anionic (up to $1830 \mathrm{mg} / \mathrm{g}$ ) dyes. The conducted investigations of the total acidity and acid-base sites on the surface of clay, magnetite-modified clay, and molybdenum disulfide-modified magnetic sorbent indicate the significant influence of the Lewis base cites on the adsorption properties of these materials.
\end{abstract}

\section{Introduction}

The nanotechnology and nanochemistry of magnetic materials are one of the most actively developing areas of modern nanoscience, which in recent years has been attracting increasing attention from researchers from various fields in chemistry, physics, biology, and medicine [1]. Magnetic nanoparticles of the size from 5 to $100 \mathrm{~nm}$ have a significant application potential in biomedicine, magnetic resonance imaging, data storage systems, various detectors and immunoassay systems, magnetically controllable fluids, environmental chemical engineering, etc. In the latter case, magnetic nanoparticles are used as sorbents or catalysts in their pure form or as a component of composite material to extract toxic pollutant (organic, heavy metal ions, etc.) substances from the aqueous medium [2-4].

In recent years, there has been an active search for methods and approaches aimed at creating new, efficient, and magnetically controllable composite sorption materials of broad functional purpose. The most promising method for creating magnetic sorbents today is the impregnation of various sorption matrices by magnetic nanoparticles $[5,6]$, which is simple in implementation and not expensive. This method is usually used for the creating sorption materials of water purification. Another popular method is layer-bylayer functionalization of magnetic nanoparticles $[7,8]$. The functionalization is used mainly for the synthesis of magnetic sorbents for analytical purposes. At the same time, 


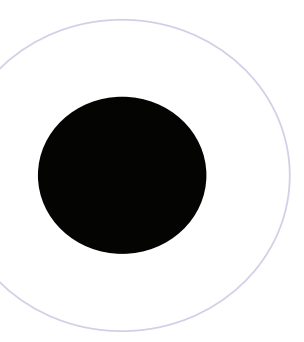

(a)

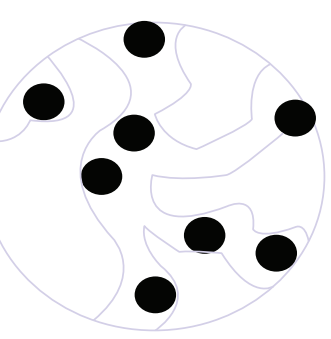

(b)

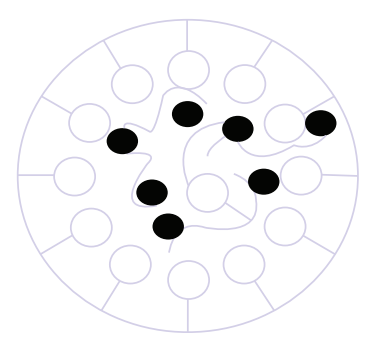

(c)

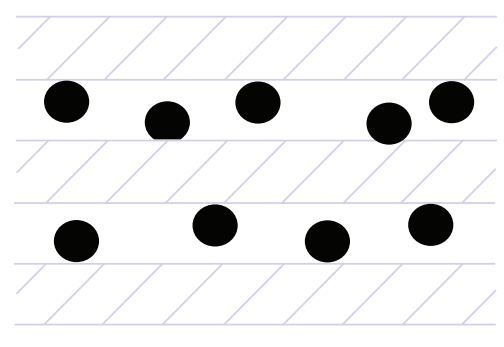

(d)

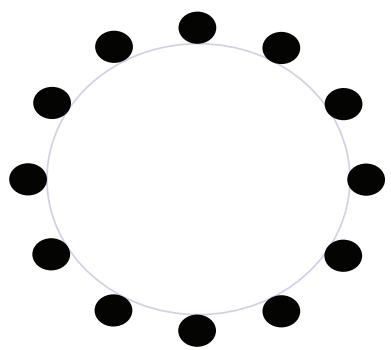

(e)

FIGURE 1: Methods of magnetic composite sorbents forming: (a) core-shell structure, (b) based on carbon materials, (c) based on polymers, (d) surface modification of clay minerals, and (e) nonporous particles, for example, metal oxides.

publications in this field, the number of which increases every year, indicate that the search continues and is still far from its completion.

An overwhelming number of publications is devoted to the synthesis and use of magnet-containing sorbents with a core-shell structure (see Figure 1(a)), which are obtained by noncovalent or covalent immobilization of various inorganic or organic compounds on the surface of previously synthesized iron oxide nanoparticles [9]. There is also a lot of research, e.g., [10-12], on the synthesis and application of magnetic composite carbon or polymer-based sorption materials with incorporated iron oxide nanoparticles (see Figures 1(b) and 1(c)). One of the most promising methods of obtaining magnetic nanocomposite sorbents include surface modification of various sorption materials by nanoscale magnetic iron oxide particles, predominantly $\mathrm{Fe}_{3} \mathrm{O}_{4}$ (see Figures 1(d) and 1(e)). This is associated with the almost unlimited opportunity to modify sorption properties of the obtained magnetic nanocomposites due to the variation of their structure whilst maintaining the relative simplicity and cheapness of their synthesis $[13,14]$.

From this point of view, the magnetic sorbents based on clay minerals are of great scientific and practical interest, since they combine unique sorption properties and low cost of clays with the possibility of their rapid separation from the suspension after the sorption process is completed by means of the magnetic field. A lot of publications are devoted to magnetic sorbents with the matrix made of bentonite, montmorillonite, kaolin, zeolite, and other clays which are usually synthesized using the method of coprecipitation [15-21].

However, in the literature, there are no comparative investigations of various approaches to obtaining such magnetic sorption nanomaterials. In [22], we carried out comparative research on the influence of the synthesis method (mechanical mixing, coprecipitation, and impregnation) on the sorption properties of magnetic nanocomposites using saponite clay as a clay mineral. We have shown that simple impregnation method is more efficient than the other mentioned methods as the obtained materials had better sorption characteristics towards dye contains at low concentrations in aqueous solutions. Also, effective and inexpensive nanocomposite sorbents based on palygorskite and spondyl clay were obtained using impregnation. These synthesized materials were characterized by high sorption capacity towards dyes, surfactants, and polyphosphates of various natures $[23,24]$.

Thus, further research is needed in the field of directed modification of clay materials with nanomagnetite in order to identify structural and sorption parameters that will lead to the creation of new, efficient, and magnetically controllable composite sorbents.

In this research, data are presented on the change in the adsorption and textural characteristics of clay matrices depending on the magnetite content; the amount of the modifier on the magnetic separation process and the moisture content of waste sorbents; and the influence of the third-phase presence (nanomolybdenum disulphide) in the magnetic mineral sorbent on its adsorption and textural properties. Thus, we attempted to analyze the possibility of directed modification of the adsorption and textural properties of various clay matrices modified with nanomagnetite by a simple impregnation method.

\section{Materials and Methods}

2.1. Magnetic Composite Clay Sorbents. Magnetic composite clay sorbents were synthesized by the method of impregnation of the corresponding clay minerals (saponite, palygorskite, and spondyl clay of Ukrainian deposits) with freshly prepared $\mathrm{Fe}_{3} \mathrm{O}_{4}$-based magnetic fluid. The method of magnetic fluid and clay-based magnetic nanocomposite synthesis is presented in detail in $[23,24]$. It has been shown that 
TABLE 1: Synthesized clay-based magnetic nanocomposites.

\begin{tabular}{lcc}
\hline Sample & Clay mineral & $\begin{array}{c}\text { Magnetite content in the } \\
\text { composite (wt.\%) }\end{array}$ \\
\hline Sap7 & Saponite & 7 \\
Sap10 & Palygorskite & 10 \\
\hline Pal7 & 7 \\
Pal10 & Spondyl clay & 10 \\
\hline Spo7 & & 7 \\
Spo10 & & 10 \\
\hline
\end{tabular}

regardless of the composition (see Table 1), the obtained magnetic composite mineral sorbents contain magnetite with a particle size of up to $10 \mathrm{~nm}$ [25].

The nanocomposite with better sorption properties was additionally modified with graphene-like $\mathrm{MoS}_{2}$, nanoparticles of which had the following characteristics: average dimensions $d[013]=2.9(2) \mathrm{nm}, d[110]=10.4(6) \mathrm{nm}$; unit cell parameters $a=0.3135(1) \mathrm{nm}, c=1.258(1) \mathrm{nm}$; and the estimated average number of S-Mo-S nanolayers $n \sim 4$ [26]. The modification of Sap7 was carried out in an aqueous suspension using an ultrasonic bath $(44 \mathrm{kHz})$ for 30 minutes. The suspension was then filtered, and after that, the obtained precipitate was dried. The synthesized Sap7- $\mathrm{MoS}_{2}$ sample contained 1 wt.\% of molybdenum disulphide and 99 wt.\% of Sap7.

2.2. Adsorption of Dyes on Magnetic Nanocomposite Sorbents. The adsorption properties of magnetic sorbents based on different clay minerals were investigated by the static adsorption of dyes of various natures. The concentration of dyes was determined using a UV/Vis spectrophotometer. The characteristics of dyes are presented in Table 2.

Sorption properties were investigated as described in $[23,24]$. The equilibrium adsorption capacities $\left(Q_{e}\right)$ were calculated according to the following equation:

$$
Q_{\mathrm{e}}=\frac{\left(C_{\mathrm{e}}-C_{0}\right) \cdot V}{m},
$$

where $C_{0}$ and $C_{\mathrm{e}}$ are the initial and equilibrium concentrations of the dyes in the solution, respectively, in $\mathrm{mg} \cdot \mathrm{l}^{-1}$; $V$ is model solution volume, in 1 ; and $m$ is the mass of sorbent sample, in $\mathrm{g}$.

2.3. Magnetic Separation. Magnetic separation of spent sorbents was carried out in a pyramidal magnetic module with magnetic field intensity over the height of the settling tank from $20 \mathrm{mT}$ to $220 \mathrm{mT}$ [25]. The residual concentration of the suspended particles of the spent magnetic sorbent was determined by turbidimetric method using a $\mathrm{UV} / \mathrm{V}$ is spectrophotometer. The moisture content of the obtained precipitate of the spent sorbent was investigated by gravimetric analysis.

2.4. Structural Adsorption Characteristics of Magnetic Nanocomposite Sorbents. The adsorption and textural characteristics of the obtained materials were carried out by low-temperature nitrogen adsorption-desorption method
( $T=77 \mathrm{~K}$ ) on Quantachrome Autosorb (Nova 2200e). The specific surface area was calculated using BrunauerEmmett-Teller (BET) equation. Adsorption pore volumes ( $V_{\text {sp }}$ ads) were calculated using a single point method. The pore size distribution of the mesopores was determinate by Barrett-Joyner-Halenda (BJH) method.

2.5. Acid-Base Properties of Magnetic Sorbent Surface. The total acidity of the surface was evaluated from the $\mathrm{pH}$ value of the isoionic point $\left(\mathrm{pH}_{\text {iip }}\right)$ by potentiometric method. $25 \mathrm{~cm}^{3}$ of double-distilled water was introduced into the potentiometric cell, and after the stabilization of the glasscombined electrode potential, $0.25 \mathrm{~g}$ of the sample was added. After certain periods of time, the $\mathrm{pH}$ of the suspension was measured under constant stirring. Thus, the curves of $\mathrm{pH}$ change over time were obtained, which reflect the acid-base state of the surface.

Investigation of the surface active sites distribution with respect to the acid-base properties was carried out with the help of Hammett method using 9 indicators with $\mathrm{pKa}$ values in the range of -0.29 to 12.8 . For this purpose, the optical density of the indicators' initial solutions with a concentration of $2.5 \mathrm{mg} / \mathrm{l}\left(D_{0}\right)$ was measured on a UV/Vis spectrophotometer. After that, the sorbent suspensions were prepared in these solutions ( $0.02 \mathrm{~g}$ of sorbent sample, $2 \mathrm{ml}$ the indicators' initial solutions, and $3 \mathrm{ml}$ of distilled water), and after reaching the adsorption equilibrium and subsequent decantation, the optical density $\left(D_{1}\right)$ was measured. In order to take into account the influence of medium $\mathrm{pH}$ change on optical density caused by the contact between the solution and the sorbent, similar suspensions were prepared in distilled water ( $~ 0.02 \mathrm{~g}$ of sample and $3 \mathrm{ml}$ of water), and after 120 minutes, an indicator initial solution was added to the decantate and the optical density $\left(D_{2}\right)$ was measured. Optical density of the solutions was determined in glass cuvettes $(10 \mathrm{~mm})$ at the wavelength corresponding to the maximum adsorption of the indicator solution. The content of active sites with a specific acidic strength $(q, \mathrm{mkg} / \mathrm{g})$ was calculated according to the following equation:

$$
q=\frac{C_{\mathrm{i}} \bullet V_{\mathrm{i}}}{D_{0}} \bullet\left[\frac{\left|D_{0}-D_{1}\right|}{m_{1}} \pm \frac{\left|D_{0}-D_{2}\right|}{m_{2}}\right],
$$

where $C_{\mathrm{i}}$ and $V_{\mathrm{i}}$ are the concentration and volume of the indicator, $\mathrm{mkg} \cdot \mathrm{l}^{-1}$ and 1 , respectively, and $m_{1}$ and $m_{2}$ are the masses of sorbent sample during measurements of $D_{1}$ and $D_{2}$, g.

\section{Results and Discussion}

3.1. Structural Sorption Properties and Sorption Capacities in Relation to Dyes of Magnetic Nanocomposites. The synthesized magnetic nanocomposites based on saponite, palygorskite, and spondyl clays initially were investigated for the determination the structural sorption properties by nitrogen adsorption-desorption method and the adsorption properties with respect to dyes of various natures.

Figures 2, 3, and 4 show the isotherms of adsorptiondesorption in nitrogen for initial clays and clay-based 
TABLE 2: Characteristics of dyes.

Dye Structural formula

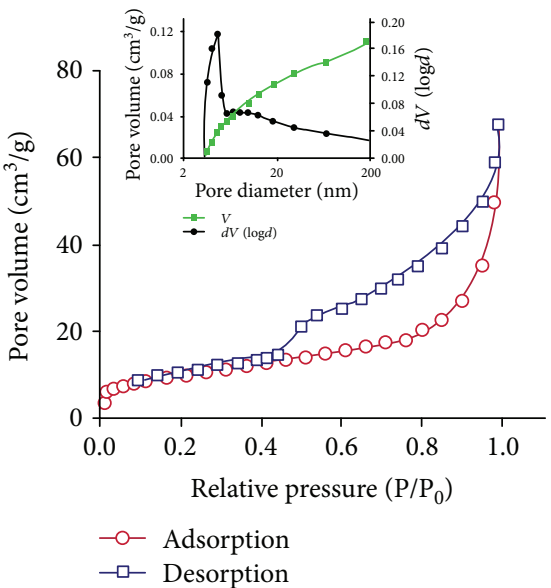

(a)

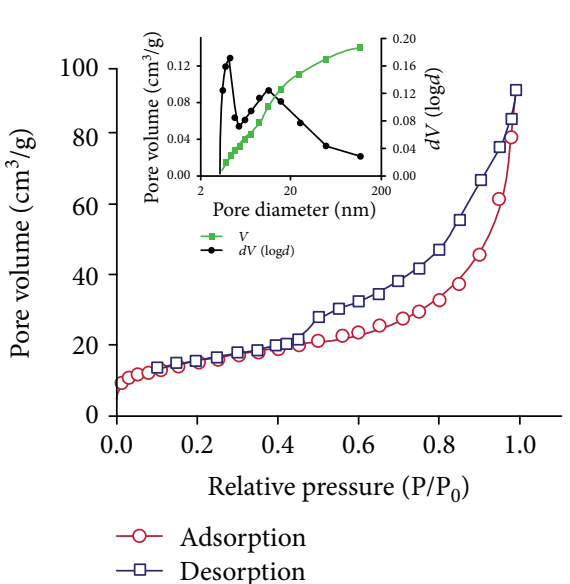

(b)

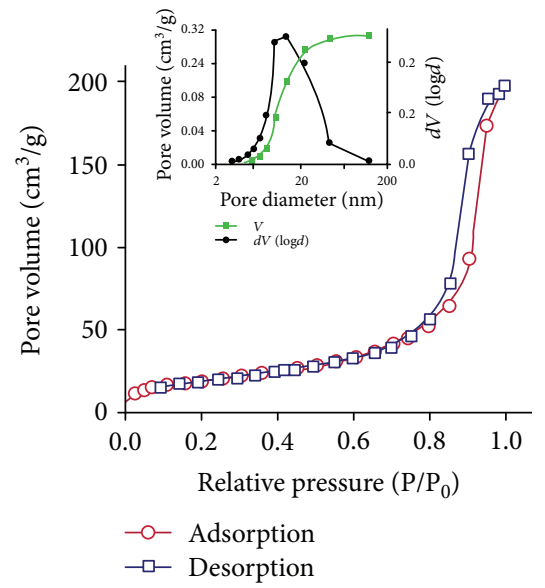

(c)

FIGURE 2: Nitrogen adsorption-desorption isotherms for saponite (a), Sap7 (b), and Sap10 (c).

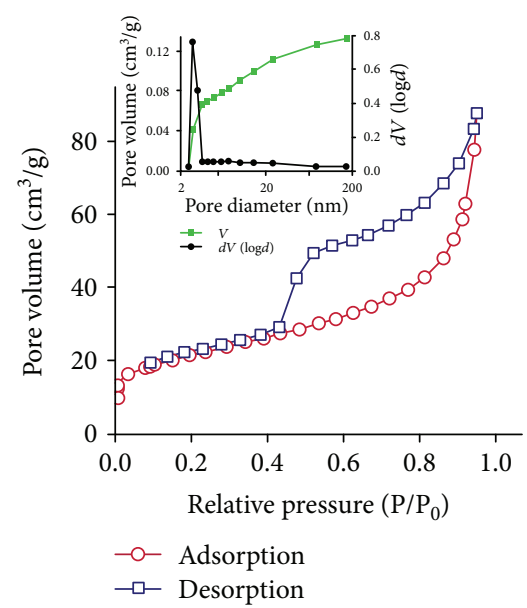

(a)

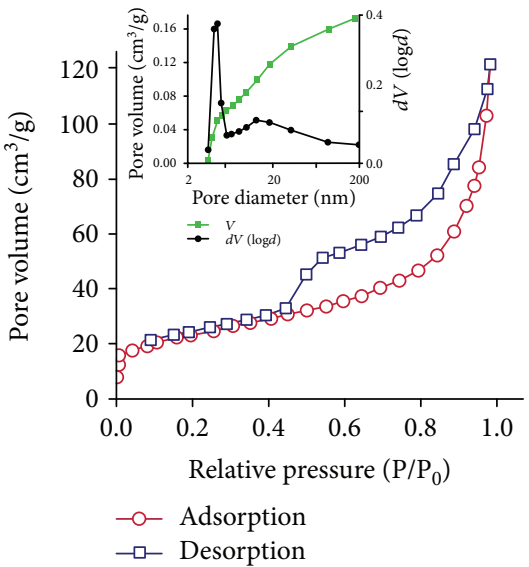

(b)

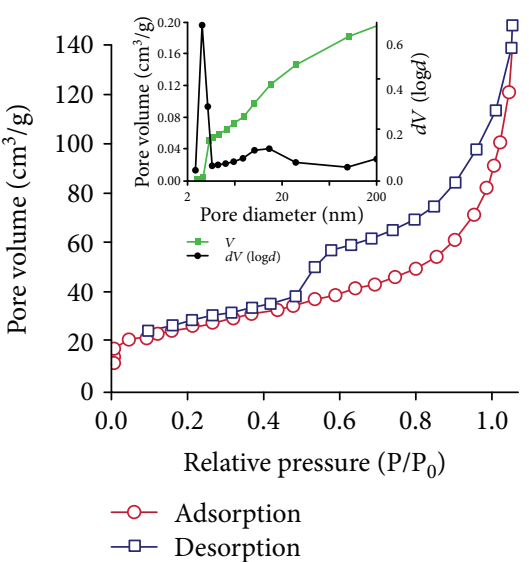

(c)

Figure 3: Nitrogen adsorption-desorption isotherms for palygorskite (a), Pal7 (b), and Pal10 (c).

magnetic nanocomposites. As it can be seen from the figures, all the presented isotherms refer to the IV type (according to IUPAC classification) that is typically of mesoporous materials [27]. All investigated initial clays (Figures 2(a), $3(\mathrm{a})$, and $4(\mathrm{a})$ ) are characterized by the average pore size in the range of $4 \mathrm{~nm}$. 


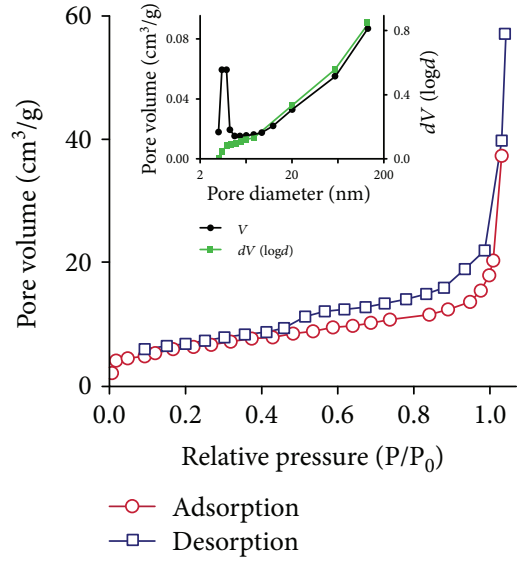

(a)

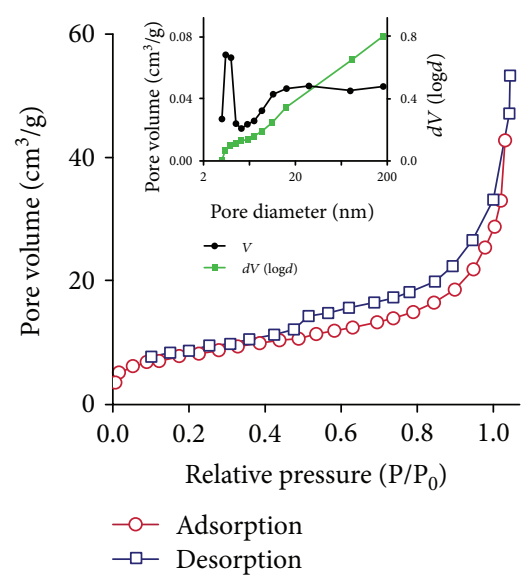

(b)

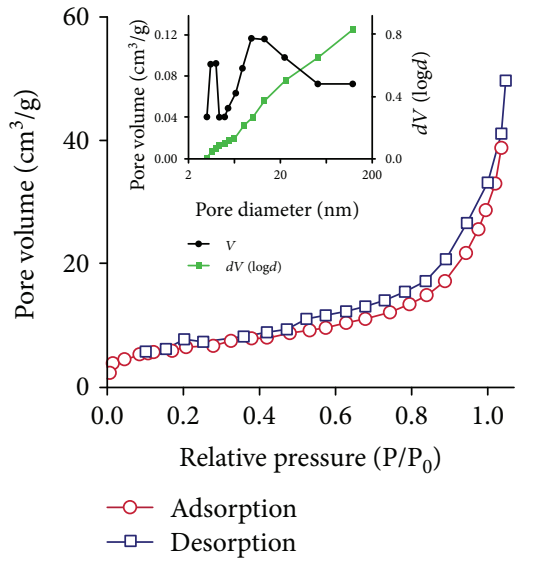

(c)

FIgURE 4: Nitrogen adsorption-desorption isotherms for spondyl slay (a), Spo7 (b), and Spo10 (c).

From the isotherms shown in Figure 2, it can be seen that the modification of saponite with magnetite has a significant effect on the adsorption and texture characteristics of composites. Thus, during the transition from the initial sample of saponite to the composites with a content of magnetite $7 \mathrm{wt} . \%$ and $10 \mathrm{wt} . \%$, a change in the capillary-condensation hysteresis loop from $\mathrm{H} 3$ through the hybrid type $\mathrm{H} 1+\mathrm{H} 3$ to $\mathrm{H} 1$ is observed. This indicates the predominant presence of cylindrical pores in the initial sample of saponite that are open on both sides, which are typical of the materials with a layered structure formed by parallel packed lamellar particles. The transition to a hybrid type of hysteresis loop for the composite with 7 wt.\% was probably caused by the deposition and partial blocking of cylindrical pores by magnetite nanoparticles. This is confirmed by the shape of nitrogen adsorption-desorption isotherm of the Sap10 sample with $10 \mathrm{wt} . \%$ of magnetite, for which spontaneous filling of pores is observed in the range of high relative pressures, $p / p_{0} 0.9-1.0$, which is typical of deadlock cylindrical pores. A similar effect was observed during adsorption of strontium ions on layered manganese oxide [28].

The increase in the BET specific surface area from $35 \mathrm{~m}^{2} / \mathrm{g}$ to $69 \mathrm{~m}^{2} / \mathrm{g}$ during the transition from the initial saponite to the Sap7 and Sap10 composites is caused by the presence of magnetite nanoparticles with a developed surface in their structure, which is confirmed by the transition of monomodal pore size distribution with a maximum of $4 \mathrm{~nm}$ for the initial clay to bimodal pore size distribution for composites with a second maximum for pores with size in the range of about $15-18 \mathrm{~nm}$. At the same time, for a sample with a maximum magnetite content in Sap10, the maximum at $18 \mathrm{~nm}$ becomes predominant. Along with the growth of the specific surface area, the modification of saponite with nanoparticles of magnetite is accompanied by an increase in the pore volume from $0.11 \mathrm{~cm}^{3} / \mathrm{g}$ to $0.31 \mathrm{~cm}^{3} / \mathrm{g}$, which is also caused by precipitation of magnetite with a developed porous structure. Thus, the modification of saponite clay with magnetite leads to the increase in the specific surface area and pore volume, as well as bimodal pore size distribution due to the formation of a secondary porous structure on the surface of native clay.

Textural characteristics of palygorskite after modification with magnetite change less significantly. For all samples, H3 type of capillary-condensation hysteresis is observed that is typical of adsorbents with layered structure and open pores of cylindrical shape. At the same time, adsorption properties (specific surface area and pore volume) of palygorskite change in a similar way as the samples based on saponite clay. The addition of magnetite also increases the specific surface area from $73 \mathrm{~m}^{2} / \mathrm{g}$ for palygorskite to $82 \mathrm{~m}^{2} / \mathrm{g}$ and $84 \mathrm{~m}^{2} / \mathrm{g}$ and pore volume from $0.13 \mathrm{~cm}^{3} / \mathrm{g}$ to $0.18 \mathrm{~cm}^{3} / \mathrm{g}$ and $0.20 \mathrm{~cm}^{3} / \mathrm{g}$ for $\mathrm{Pal} 7$ and $\mathrm{Pal} 10$, respectively. On the pore size distribution curves, along with the maximum at $4 \mathrm{~nm}$, an insignificant second peak appears with a maximum of about $18 \mathrm{~nm}$. It is obvious that changes in adsorption characteristics are associated with the formation of the secondary porous magnetite structure, while preservation of textural characteristics is caused by the absence of pores blocking the initial palygorskite during the precipitation of magnetite for Pal 7 and Pal 10 samples.

Sorbent samples based on spondyl clay are characterized by similar $\mathrm{H} 2$ type of hysteresis loop that is typical of slit-like pores, regardless of the magnetite content. Although spondyl clay is characterized by a predominantly average mesopore size of $4 \mathrm{~nm}$, macropores (see Figure 4(a)) are also present in its structure. With the increase in magnetite content, an insignificant increase in the adsorption characteristics is observed, namely, specific surface area increases from $21 \mathrm{~m}^{2} / \mathrm{g}$ to $31 \mathrm{~m}^{2} / \mathrm{g}$ and $37 \mathrm{~m}^{2} \mathrm{~g}$ and pore volume from $0.08 \mathrm{~cm}^{3} / \mathrm{g}$ to $0.09 \mathrm{~cm}^{3} / \mathrm{g}$ and $0.12 \mathrm{~cm}^{3} / \mathrm{g}$ for the initial spondyl clay and Spo7 and Spo10 composites, respectively. It should be noted that similar to the cases considered above, the modification with magnetite also leads to the formation of the secondary porous structure on the surface of spondyl clay macropores with an average mesopore diameter of $20 \mathrm{~nm}$, the amount of which increases with the increase of the $\mathrm{Fe}_{3} \mathrm{O}_{4}$ modifier.

Thus, different regularities of the adsorption and textural characteristics change of composites are observed that depend 


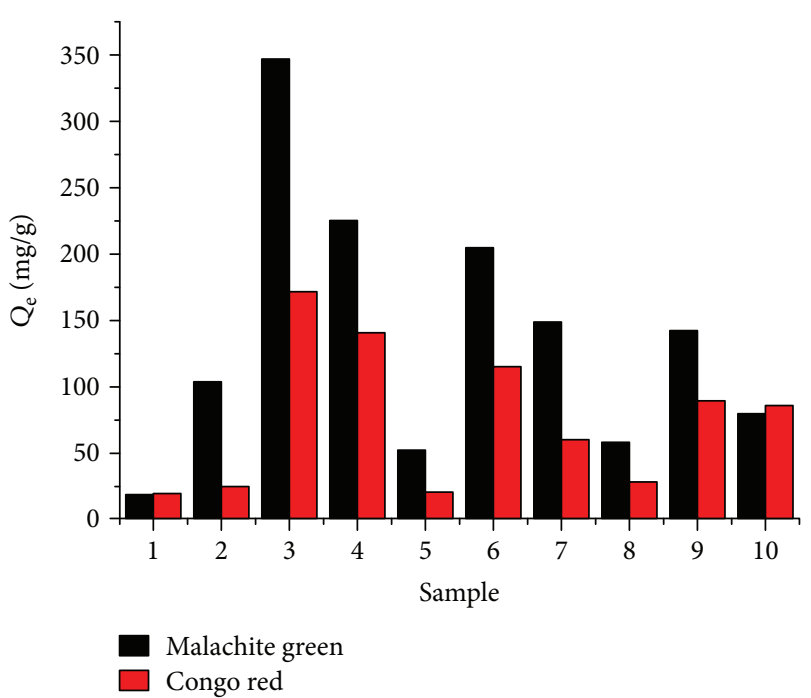

FIGURE 5: Sorption capacities of the sorbent samples regarding malachite green and Congo red: 1-magnetite, 2-saponite, 3-Sap7, 4-Sap10, 5-palygorskite, 6-Pal7, 7-Pal10, 8-spondyl clay, 9-Spo7, 10-Spo10.

on the type and porous structure of the initial clay. In all cases, the introduction of magnetite into the structure of clay minerals leads to the formation of the secondary porous structure and is accompanied by an increase in the specific surface area and pore volume of nanocomposite materials.

Sorption capacities of all native clays, as well as claybased magnetic nanocomposites and magnetite with respect to malachite green and Congo red, are shown in Figure 5. According to the diagram shown in Figure 5, saponite-based sorbents demonstrate the best sorption properties in both dyes, which are characterized by larger surface areas than spondyl clay-based samples and smaller surface areas than palygorskite-based sorbents. In all cases, when clays are modified with magnetite, sorption properties are improved and the largest capacity is observed for magnetic sorbents with magnetite content of $7 \mathrm{wt} . \%$. It should be noted that in spite of blocking the initial pores of the saponite, Sap10 is still quite active with regard to dyes of various natures.

An additional investigation of magnetite sorption properties has shown that it has the lowest sorption capacity with respect to both dyes. The highest sorption capacity $(350 \mathrm{mg} / \mathrm{g}$ and $170 \mathrm{mg} / \mathrm{g}$ with respect to malachite green and Congo red, respectively) belongs to the magnetic nanocomposite sorbent based on saponite clay Sap7.

Thus, it is possible to establish a synergetic effect when nanomagnetite is introduced into a clay matrix in all cases.

\subsection{Magnetic Separation of the Spent Magnetic Sorbents.} Such important technological parameters as residual concentration of sorbent particles for a certain time period and humidity of precipitation were investigated after magnetic separation of spent sorbents.

The results of investigations of the spent sorbents separation using magnetic separation in the magnetic module are presented in Figure 6. The figure shows the residual concentrations of suspended particles of clays and claybased magnetic sorbents in the solution after 30-minute magnetic separation, and the moisture of the precipitates after their separation from the solution to be purified.

As it can be seen from Figure 6, in all cases, that the modified clays (positions 2 and 3 ) are separated from the solution 5 times faster than native clay materials. Moisture content of spent magnetic sorbent precipitates is at least 3.5 times lower than that of clay minerals.

The studies above indicate a significant perspective on the creation of magnetic nanocomposite sorbents based on natural clay matrices, which, as shown, are characterized by better textural characteristics and adsorption properties than natural clays. Also, their use will make it possible to get much faster separation of spent sorbents from the solution and obtain precipitates with lower moisture content.

So, based on the obtained results on textural characteristics, adsorption properties, and technological parameters for the investigation of additional modification with graphenelike particles of molybdenum disulphide, magnetic nanocomposite sorbent Sap7 was chosen.

\subsection{Effect of $\mathrm{MoS}_{2}$ Modification on Sorption and Acid-Base} Properties of Magnetic Nanocomposite Based on Sap7. The change in the sorption activity of the magnetic sorbent Sap7 after its modification with molybdenum disulphide, as well as comparison with the initial saponite clay, is shown in Figure 7.

As it can be seen from Figure 7, an additional modification of the magnetic sorbent Sap7 with molybdenum disulphide results in a significant increase in the sorption capacity, namely, the sorption capacity of Sap7- $\mathrm{MoS}_{2}$ with respect to malachite green is $1100 \mathrm{mg} / \mathrm{g}$ that is 11 times and 3.2 times higher than the same for saponite and Sap7, respectively. The sorption capacity of Sap7- $\mathrm{MoS}_{2}$ with respect to Congo red is significantly higher and is at the level of $1830 \mathrm{mg} / \mathrm{g}$ that is 62 and 10.4 times more than the same for saponite and Sap7, accordingly.

The increase in the sorption capacity of Sap7- $\mathrm{MoS}_{2}$ for both dyes cannot be explained only by changes in their textural characteristics. In our opinion, such sudden leap of the sorption capacity can be caused either by the appearance of additional surface active centers on the surface of the magnetic composite material or by the photocatalytic activity of the third-phase molybdenum disulphide in the composition of the magnetic nanocomposite Sap7-MoS 2 , which reveals in the visible light area [29]. In order to determine the first assumption, investigations were carried out concerning the total acidity of the surface and the distribution of surface centers along the acid-base properties of these three samples.

Figure 8 shows the $\mathrm{pH}$ changes of the sorbent suspension in double-distilled water over time for saponite, Sap7, and Sap7- $-\mathrm{MoS}_{2}$. As it can be seen from the figure, in all cases, Lewis base centers predominate. After reaching the equilibrium, the value of the isoionic point for saponite, Sap7, and Sap7- $\mathrm{MoS}_{2}$ was 9.3, 8.4, and 9.1, respectively. The steadystate $\mathrm{pH}$ values indicate the base state of the surface of all the investigated samples. Moreover, saponite is characterized by the highest basicity while Sap7 by the lowest. 


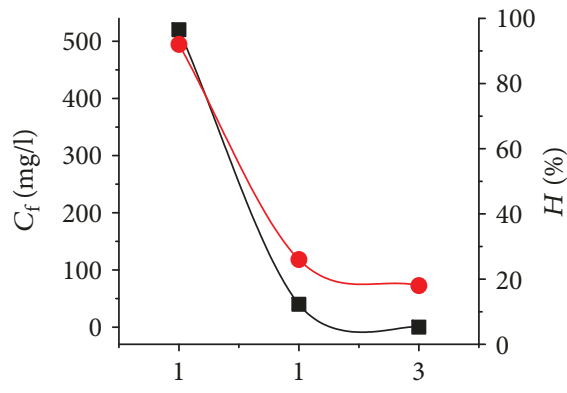

$\rightarrow-C_{\mathrm{f}}$

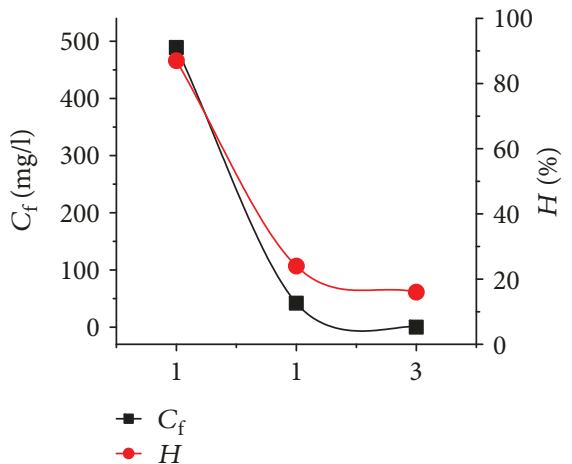

(b)

(a)

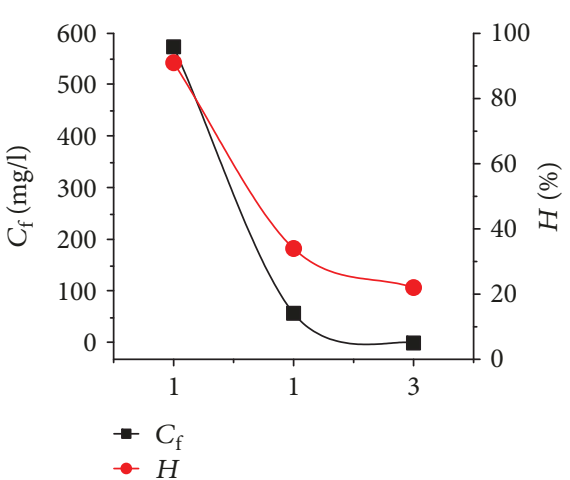

(c)

Figure 6: Residual concentration $\left(C_{\mathrm{f}}\right)$ of spent sorbents particles and their moisture content $(H)$ after magnetic separation for 30 min: (a) for saponite and its magnetic composites, (b) for palygorskite and its magnetic composites, (c) for spondyl clay and its magnetic composites: 1 -initial clays, 2 -modified clays with $7 \mathrm{wt} . \%$ of magnetite, and 3-modified clays with $10 \mathrm{wt} . \%$ of magnetite.

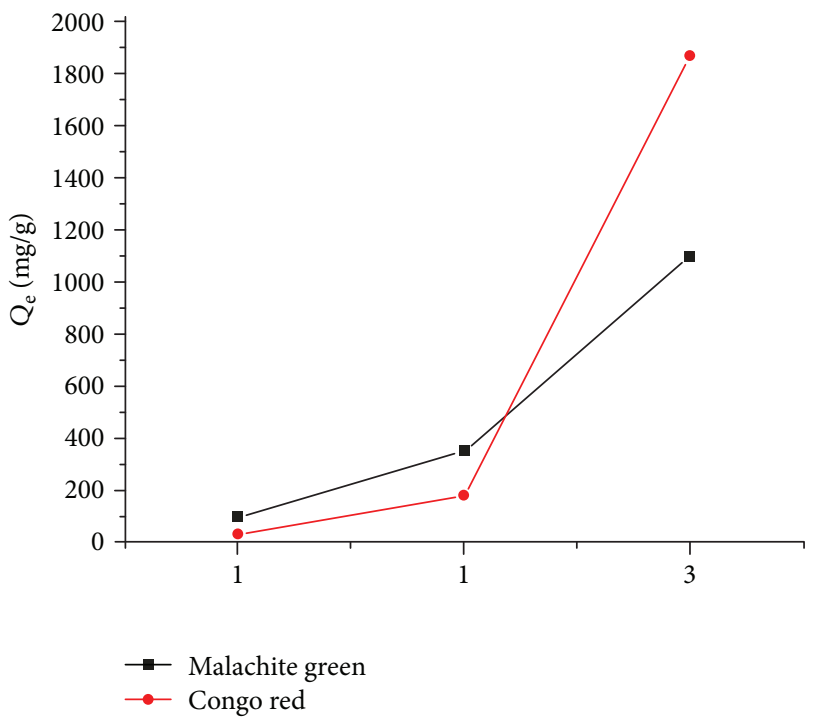

FIGURE 7: The change in the sorption activity: 1-saponite, 2-Sap7, and 3-Sap7- $\mathrm{MoS}_{2}$.

The following Hammett indicators were selected for the investigations: o-nitroaniline $(\mathrm{pK}=-0.29)$, fuchsine $(\mathrm{pK}=2.1)$, bromophenol blue $(\mathrm{pK}=3.9)$, methyl red $(\mathrm{pK}=5.25)$, bromothymol blue $(\mathrm{pK}=6.8)$, phenol red

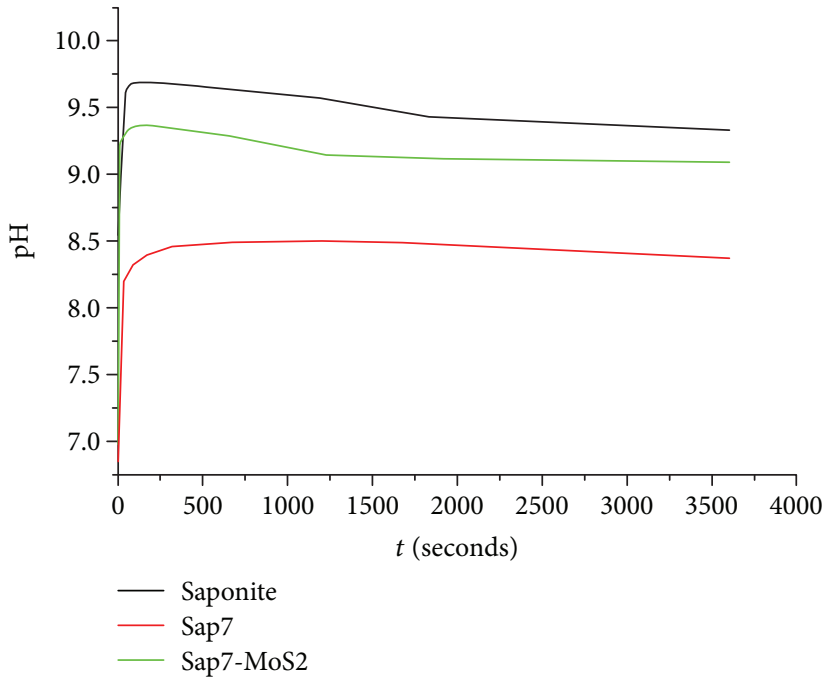

Figure 8: $\mathrm{pH}$ change of the aqueous suspensions over time for saponite, Sap7, and Sap7-MoS .

( $\mathrm{pK}=7.6)$, thymol blue $(\mathrm{pK}=8.8)$, and indigo carmine $(\mathrm{pK}=12.8)$. Figure 9 shows the distribution curves of the adsorption centers of Hammett indicators on the surface of saponite, Sap7, and Sap7-MoS 2 in the aqueous medium. 


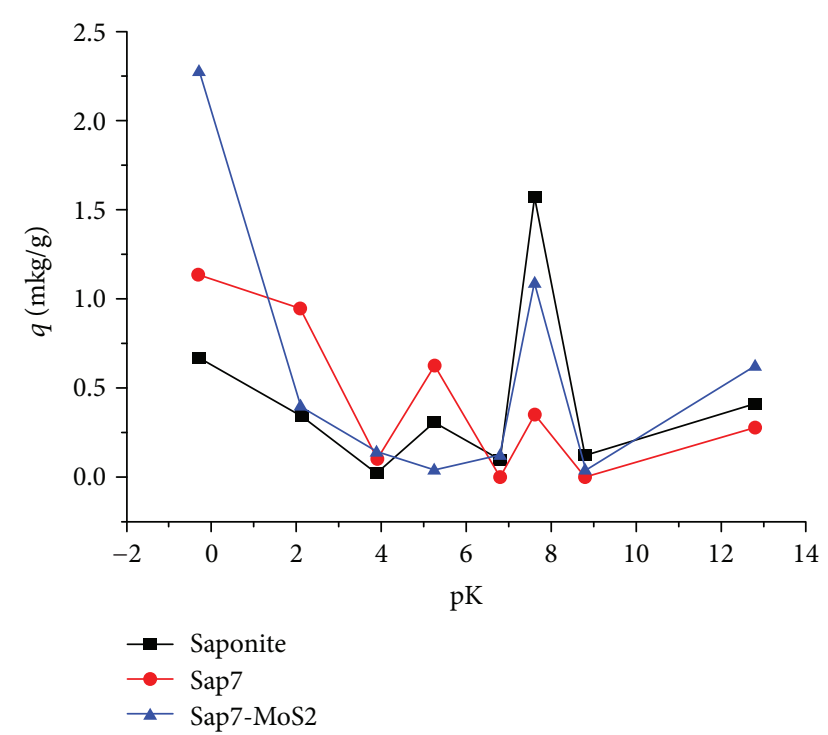

FIGURE 9: Distribution of the adsorption centers of indicators on the surface of sorbent samples.

Analysis of the obtained data on the distribution of the adsorption centers on the surface of saponite indicates the predominance of Brönsted base sites $(\mathrm{pK}=7.6, \mathrm{pK}=12.8)$ and Lewis base sites $(\mathrm{pK}=-0.29)$, as well as a small number of Brönsted acid sites ( $\mathrm{pK}=2.1, \mathrm{pK}=5.25)$.

Modification of the saponite surface with $7 \mathrm{wt} . \%$ of magnetite leads to the decrease in the number of Brönsted base sites $(\mathrm{pK}=7.6)$ and to the increase in the number of Brönsted acid sites $(\mathrm{pK}=5.25)$, which explains the decrease in $\mathrm{pH}_{\text {iip }}$ compared to saponite, as well as the higher adsorption affinity for anionic dye compared to saponite. The number of Lewis base sites $(\mathrm{pK}=-0.29)$ increases compared with saponite in Sap7.

Additional modification of the magnetic sorbent Sap7 with molybdenum disulfide increases the number of the Brönsted base sites ( $\mathrm{pK}=7 \mathrm{ю}, \mathrm{pK}=12.8$ ) on its surface in comparison with Sap7, but still there are less of them than in saponite. In addition, modification with graphene-like particles of $\mathrm{MoS}_{2}$ leads to an even more significant increase in the number of Lewis base sites $(\mathrm{pK}=-0.29)$.

Thus, the increase in the Lewis base sites content from saponite to Sap7 and then to Sap7-MoS leads to the increase in adsorption capacity towards malachite green, which is a cationic dye. The increase in sorption activity with respect to Congo red is caused by both the increase in the number of Brönsted acid sites (especially for Sap7) and, possibly, by the photocatalytic activity of molybdenum disulphide in Sap7- $-\mathrm{MoS}_{2}$.

\section{Conclusions}

The changes in the textural characteristics of clay matrices after their modification with nanomagnetite in the amount of $7 \mathrm{wt} . \%$ and $10 \mathrm{wt} . \%$ have been investigated and analyzed. It has been shown that in all cases the introduction of magnetite into the structure of clay minerals leads to the formation of the secondary porous structure and is accompanied by the increase in the specific surface area and pore volume of nanocomposite materials.

As a result of magnetic separation of both magnetic nanocomposites and clay sorbents, it has been shown that magnetic sorbents are separated from the suspension at least 5 times faster than clays, and the moisture content of the precipitates decreases by 3.5-4.75 times. It has been established that the modification of clay matrices with nanomagnetite content that exceeds $7 \mathrm{wt} . \%$ is unreasonable due to the decrease in adsorption properties in all cases.

The additional modification of magnetic sorbents with graphene-like molybdenum disulphide (Sap7- $\mathrm{MoS}_{2}$ ) significantly changes their adsorption and surface properties. The sorption capacity of the triple magnetic composite with respect to the cationic dye increases from $350 \mathrm{mg} / \mathrm{g}$ to $1100 \mathrm{mg} / \mathrm{g}$ and to the anionic dye from $176 \mathrm{mg} / \mathrm{g}$ to $1830 \mathrm{mg} / \mathrm{g}$. The increase in the sorption capacity of Sap7$\mathrm{MoS}_{2}$ for both dyes is related, in our opinion, to the increase in the number of the Lewis base sites and increase in the number of Brönsted acid sites.

The obtained results demonstrate the considerable prospects for the creation of magnetic nanocomposite sorbents based on natural clay matrices, which, as shown, are characterized by better textural characteristics, adsorption properties, and technological parameters regarding separation after the sorption process than natural clays. In this case, additional modification with graphene-like molybdenum disulphide makes it possible to create absolutely new highly efficient magnetic nanocomposite sorbents of multifunctional purpose.

\section{Data Availability}

No data were used to support this study.

\section{Conflicts of Interest}

The authors declare that there is no conflict of interest regarding the publication of this paper.

\section{Acknowledgments}

The authors thank the staff of the Institute of Bioorganic Chemistry and Petrochemistry of the National Academy of Sciences for their help in conducting some studies. This research was supported by the Ministry Education and Science of Ukraine (grant number M/20-2018).

\section{References}

[1] V. Singh, R. Madugundo, A. Annadi, B. Bhoi, K. D. Chandrasekhar, and M. Bohra, "Synthesis, properties and applications of multifunctional magnetic nanostructures," Journal of Nanomaterials, vol. 2017, Article ID 2638715, 2 pages, 2017.

[2] G. Gangadhar, U. Maheshwari, and S. Gupta, "Application of nanomaterials for the removal of pollutants from effluent streams," Nanoscience \&Nanotechnology-Asia, vol. 2, no. 2, pp. $140-150,2012$. 
[3] X. Qu, P. J. J. Alvarez, and Q. Li, "Applications of nanotechnology in water and wastewater treatment," Water Research, vol. 47, no. 12, pp. 3931-3946, 2013.

[4] C. Santhosh, V. Velmurugan, G. Jacob, S. K. Jeong, A. N. Grace, and A. Bhatnagar, "Role of nanomaterials in water treatment applications: a review," Chemical Engineering Journal, vol. 306, pp. 1116-1137, 2016.

[5] T. Kanjilal and C. Bhattacharjee, "Chapter 1: Green applications of magnetic sorbents for environmental remediation," Materials Research Forum LLC Book "Organic Pollutants in Wastewater I", vol. 29, pp. 1-41, 2018.

[6] J. Zhu, S. Wei, M. Chen et al., "Magnetic nanocomposites for environmental remediation," Advanced Powder Technology, vol. 24, no. 2, pp. 459-467, 2013.

[7] A. E. Karatapanis, Y. Fiamegos, and C. D. Stalikas, "Silicamodified magnetic nanoparticles functionalized with cetylpyridinium bromide for the preconcentration of metals after complexation with 8-hydroxyquinoline," Talanta, vol. 84, no. 3, pp. 834-839, 2011.

[8] K. Aguilar-Arteaga, J. A. Rodriguez, and E. Barrado, "Magnetic solids in analytical chemistry: a review," Analytica Chimica Acta, vol. 674, no. 2, pp. 157-165, 2010.

[9] C. Li, L. Chen, and W. Li, "Magnetic titanium oxide nanoparticles for hemimicelle extraction and HPLC determination of organophosphorus pesticides in environmental water," Microchimica Acta, vol. 180, no. 11-12, pp. 1109-1116, 2013.

[10] L. C. A. Oliveira, R. V. R. A. Rios, J. D. Fabris, V. Garg, K. Sapag, and R. M. Lago, "Activated carbon/iron oxide magnetic composites for the adsorption of contaminants in water," Carbon, vol. 40, no. 12, pp. 2177-2183, 2002.

[11] Y. Zhang, B. Wu, H. Xu et al., "Nanomaterials-enabled water and wastewater treatment," NanoImpact, vol. 3-4, pp. 22-39, 2016.

[12] A. V. Pastukhov, V. A. Davankov, V. V. Volkov, S. V. Amarantov, and K. I. Lubentsova, "Structure and sorption properties of hypercrosslinked polystyrenes and magnetic nanocomposite materials based on them," Journal of Polymer Research, vol. 21, no. 4, 2014.

[13] S. De Gisi, G. Lofrano, M. Grassi, and M. Notarnicola, "Characteristics and adsorption capacities of low-cost sorbents for wastewater treatment: a review," Sustainable Materials and Technologies, vol. 9, pp. 10-40, 2016.

[14] N. O. Mykhailenko, O. V. Makarchuk, T. A. Dontsova, S. Gorobets, and I. M. Astrelin, "Purification of aqeous media by magnetically operated saponite sorbents," Eastern-European Journal of Enterprise Technologies, vol. 4, no. 10, pp. 13-20, 2015.

[15] J. Vereš and Z. Orolínová, "Study of the treated and magnetically modified bentonite as possible sorbents of heavy metals," Acta Montanistica Slovaca, vol. 14, no. 2, pp. 152-155, 2009.

[16] F. S. Hashem, "Adsorption of methylene blue from aqueous solutions using $\mathrm{Fe}_{3} \mathrm{O}_{4}$ /bentonite nanocomposite," Scientific Reports, vol. 549, pp. 1-5, 2012.

[17] J. Chang, J. Ma, Q. Ma et al., "Adsorption of methylene blue onto $\mathrm{Fe}_{3} \mathrm{O}_{4}$ /activated montmorillonite nanocomposite," Applied Clay Science, vol. 119, no. 1, pp. 132-140, 2016.

[18] A. Magdy, Y. O. Fouad, M. H. Abdel-Aziz, and A. H. Konsowa, "Synthesis and characterization of $\mathrm{Fe}_{3} \mathrm{O}_{4} /$ kaolin magnetic nanocomposite and its application in wastewater treatment," Journal of Industrial and Engineering Chemistry, vol. 56, pp. 299-311, 2017.
[19] L. C. A. Oliveira, D. I. Petkowicz, A. Smaniotto, and S. B. C. Pergher, "Magnetic zeolites: a new adsorbent for removal of metallic contaminants from water," Water Research, vol. 38, no. 17, pp. 3699-3704, 2004.

[20] L. C. A. Oliveira, R. V. R. A. Rios, J. D. Fabris, K. Sapag, V. K. Garg, and R. M. Lago, "Clay-iron oxide magnetic composites for the adsorption of contaminants in water," Applied Clay Science, vol. 22, no. 4, pp. 169-177, 2003.

[21] T. Szabó, A. Bakandritsos, V. Tzitzios et al., "Magnetic iron oxide/clay composites: effect of the layer silicate support on the microstructure and phase formation of magnetic nanoparticles," Nanotechnology, vol. 18, no. 28, article 285602, 2007.

[22] O. V. Makarchuk, T. A. Dontsova, and I. M. Astrelin, "Magnetic clay sorbent for the removal of dyes from aqueous solutions," Research Bulletin of the National Technical University of Ukraine "Kyiv Polytechnic Institute", vol. 0, no. 6, pp. 109-114, 2015.

[23] O. V. Makarchuk, T. A. Dontsova, and I. M. Astrelin, "Magnetic nanocomposites as efficient sorption materials for removing dyes from aqueous solutions," Nanoscale Research Letters, vol. 11, no. 1, pp. 161-167, 2016.

[24] O. Makarchuk, T. Dontsova, A. Perekos, A. Skoblik, and Y. Svystunov, "Magnetic mineral nanocomposite sorbents for wastewater treatment," Journal of Nanomaterials, vol. 2017, Article ID 8579598, 7 pages, 2017.

[25] O. V. Makarchuk, T. A. Dontsova, and A. E. Perekos, "Magnetic nanocomposite sorbents on mineral base," Nanophysics, Nanomaterials, Interface Studies, and Applications, vol. 195, pp. 705-719, 2017.

[26] T. A. Dontsova, L. M. Kulikov, and I. M. Astrelin, "Adsorption photocatalytic properties of micronic and graphene (2D) nanoparticles of molybdenum dichalcogenides," Journal of Water Chemistry and Technology, vol. 39, no. 3, pp. 132-137, 2017.

[27] M. Thommes, K. Kaneko, A. V. Neimark et al., "Physisorption of gases, with special reference to the evaluation of surface area and pore size distribution (IUPAC technical report)," Pure and Applied Chemistry, vol. 87, no. 9-10, 2015.

[28] A. I. Ivanets, V. G. Prozorovich, T. F. Kouznetsova et al., "Sorption behavior of strontium ions on manganese oxides with tunnel structure," Journal of Radioanalytical and Nuclear Chemistry, vol. 316, no. 2, pp. 673-683, 2018.

[29] M. Wu, L. Li, N. Liu, D. J. Wang, Y. C. Xue, and L. Tang, "Molybdenum disulfide (MoS2) as a co-catalyst for photocatalytic degradation of organic contaminants: a review," Process Safety and Environment Protection, vol. 118, pp. 40--58, 2018. 


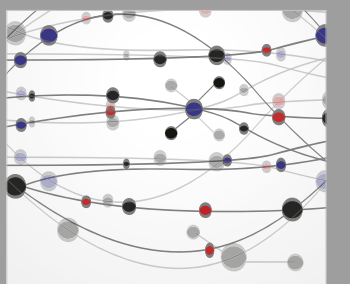

The Scientific World Journal
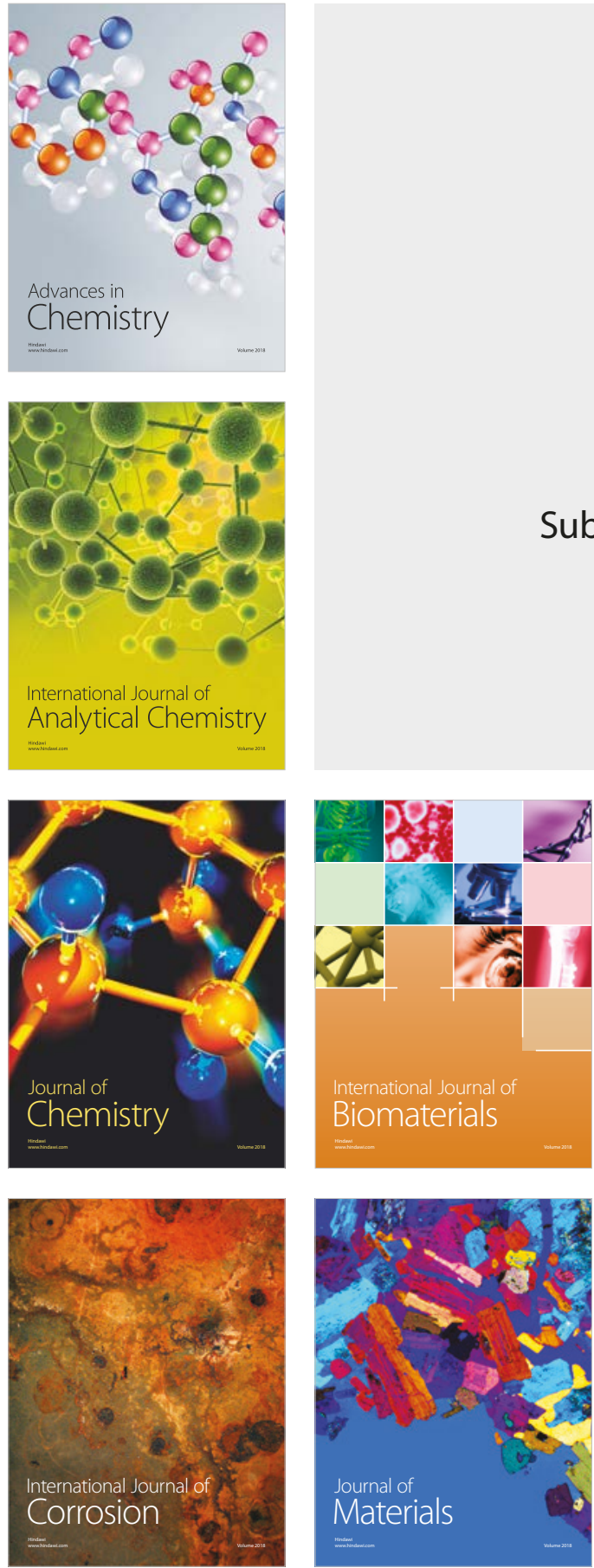

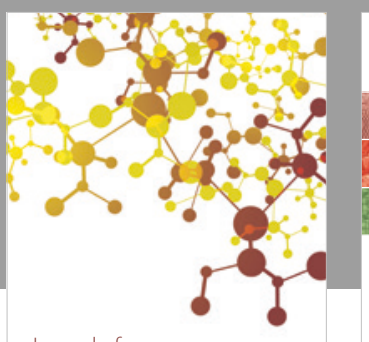

Journal of

Applied Chemistry
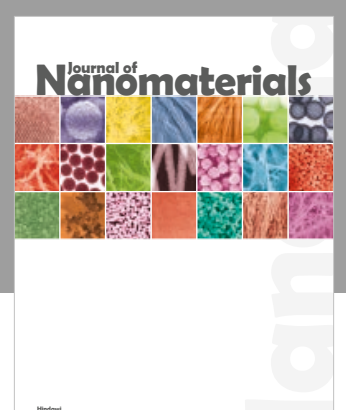

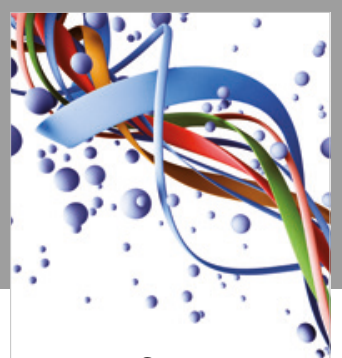

Scientifica

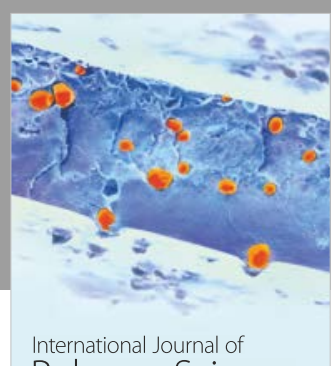

Polymer Science

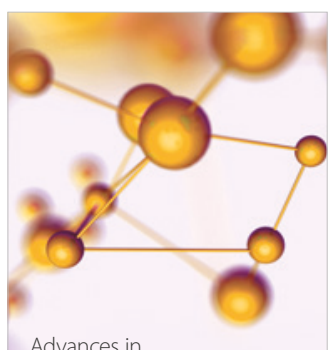

Physical Chemistry
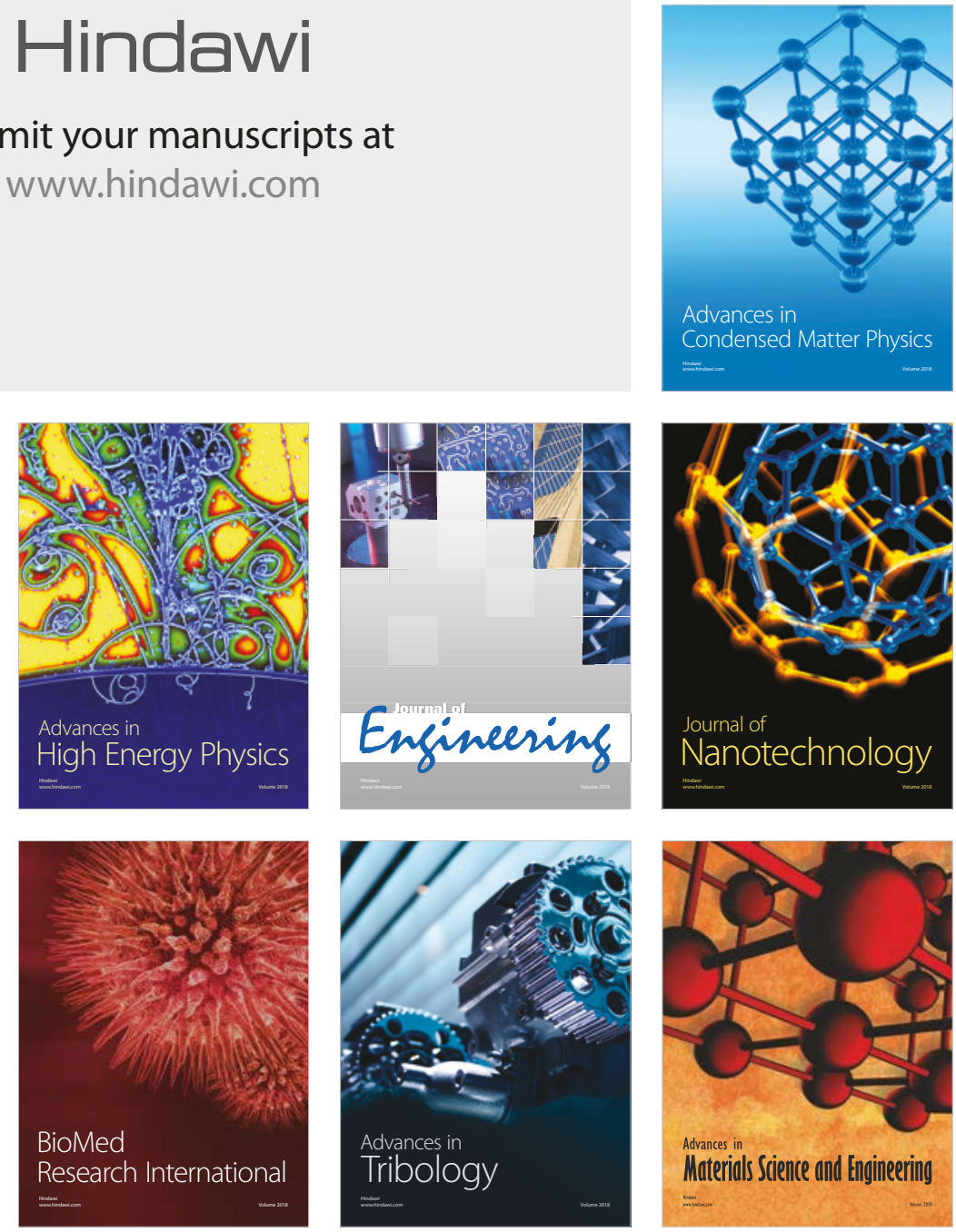